\title{
F. Nietzsche ou a "política" como "antipolítica"
}

\author{
Céline Denat**
}

\begin{abstract}
Resumo: Este artigo visa a discutir a relação de Nietzsche com a política. O filósofo alemão geralmente é visto como um pensador que critica ferozmente a política de sua época, mas que não possui nenhuma proposta concreta. Embora o próprio filósofo reforce essa imagem ao se declarar apolítico, o texto mostra em que sentido Nietzsche é apolítico e mesmo antipolítico, e revela o surgimento de um novo significado para a política. Palavras-chave: cultura - fisiopsicologia - grande política - política
\end{abstract}

“Todas as grandes épocas da cultura são épocas de declínio político: o que é grande no sentido da cultura era apolítico, mesmo antipolítico." (GD/CI Was den Deutschen abgeht 4, KSA 6.106).

Bertrand Russell, em sua História da filosofia moderna, compraz-se em ironizar a pouca consistência e o rigor da reflexão e, mais ainda, do pretenso projeto político de Nietzsche: quem se contentou, de fato, em anunciar com grandiloquência sua vontade de transformar o homem e a cultura, sem ser capaz, entretanto, de determinar suficientemente a natureza de suas exigências e das normas políticas que pretendia implementar para esse fim. Ele se contentou com

\footnotetext{
* Tradução de Wilson Antonio Frezzatti Jr.

** Professora da Universidade de Reims, Reims, França. E-mail: celine@wanadoo.fr.
} 
afirmações radicais (por exemplo, os perigos inerentes à democracia e ao igualitarismo, e, em contrapartida, o valor do aristocratismo), sem refletir sobre elas nem as determinar suficientemente, de modo que os propósitos de Nietzsche acerca desses aspectos (dos quais Russell não hesita em perguntar se eles não se reduziriam a "fantasmas de poder de um inválido") seriam completamente comparáveis aos violentos, mas vãos, anúncios do Rei Lear: “... - I will do such things - / What they are yet I know not, / but they shall be / The terrors of the earth!'." A violência dessa acusação é, no caso de Russell, fundada sobre uma leitura claramente parcial, e tendenciosa, das obras de Nietzsche, que o levam a numerosas interpretações equivocadas dessas obras. Em todo caso, há justamente aqui uma dificuldade que todo leitor de Nietzsche, em algum momento, efetivamente se confrontará: procurar, nos escritos do autor de Para além de bem e mal, uma teoria ou até mesmo um projeto político determinado, a descrição - conforme a exigência clássica das filosofias anteriores - da melhor constituição, ou ao menos de uma organização política e de normas jurídicas desejáveis, só poderia de fato resultar em decepção. É verdade, assim, segundo um preconceito corrente, que a filosofia de Nietzsche é essencialmente crítica (contra o Estado, os valores democráticos, etc.), e que ela recusa e rejeita toda proposta de reconstrução daquilo que ela pretende colocar do avesso [renverser]? Em um texto de 1862, intitulado Fatum e história, o jovem Nietzsche constatou com alguma inquietude: "Tentei tudo negar; é fácil demolir, mas construir!...". Teria a filosofia de Nietzsche justamente tropeçado nessa dificuldade que constitui a necessidade de reconstruir após haver destruído, de não somente se opor, mas ser capaz de propor um projeto político novo - dificuldade da qual, no entanto, ele estaria claramente consciente?

1 King Lear, II 4 in RUSSELL, B. History of Western Philosophy. London: Routledge, 1991. (rep.) p. 734. NT: “... farei tais coisas... o que serão, ainda não sei, mas serão o terror da terra” (SHAKESPEARE, W. Obra completa. Trad. F. C. de A. C. Medeiros e O. Mendes. Rio de Janeiro: Nova Aguilar, 1989. v. I. p. 661). 
Essa dificuldade é ainda mais clara quando o próprio Nietzsche parece apresentar essa falta de interesse pela reflexão política como uma escolha, e uma escolha da qual ele se orgulha, como testemunha sua correspondência: "Felizmente para mim, quase nunca se fala de política, pois eu não sou um zôon politikon, e essas são coisas em face das quais eu me eriço como um porco-espinho", escrita em 1868 a seu amigo Rohde; "Ninguém vive mais do que eu apartado dessas questões [das questões políticas ou sociais]", afirma ainda em uma carta a Theodor Curti datada do verão de 1882 , "eu nunca falo sobre isso, eu não sei nada sobre os acontecimentos mais conhecidos, e mesmo não leio nunca os jornais - e de tudo isso eu fiz um privilégio!". E sabe-se que, em seus últimos escritos, Nietzsche caracteriza-se como um pensador "antipolítico" (como "o último alemão antipolítico", EH/EH, Warum ich so weise Bin, 3, KSA 6.2682), e faz, ao mesmo tempo, o louvor àquilo que é, não somente "apolítico", mas mais precisamente "antipolítico" (GD/CI, Was den Deutschen abgeht, 4, KSA 6.106).

Ao mesmo tempo, é verdade que se encontra nos escritos nietzschianos numerosas declarações que tocam certamente a esfera política, algumas declarações críticas por um lado, como mencionado acima, mas, por outro lado, outras que parecem ao menos delinear positivamente as grandes linhas do que ele parece preconizar nessa matéria: a consideração e a hierarquização dos indivíduos, em oposição ao privilégio concedido à totalidade estatal e aos valores democráticos, que tendem à "igualação" e, assim, à "mediocrização" do homem (JGB/BM 203 e 242, KSA 5.126-128 e 182-183); a preferência concedida, em outras palavras, aos valores de tipo "aristocrático", dos quais ele afirma muitas vezes o caráter mais favorável ao homem (JGB/BM 257, KSA 5.205-206) e à cultura (AC/AC 43, KSA 6.217-218); a exigência que as normas, ou mais

2 Essa fórmula aparece ao menos na primeira versão desse parágrafo de Ecce Homo, que a edição Colli e Montinari substitui pela versão que Nietzsche desejava ver publicada, e que foi retirada por P. Gast. Essa primeira versão encontra-se citada no aparato crítico (KSA 14.472). 
Denat, C.

radicalmente os novos valores, não sejam somente intelectualmente pensadas, mas incorporadas, a fim de que elas tenham sobre os homens uma autoridade autêntica.

Essa aparente dualidade das declarações de Nietzsche suscitou nestes últimos anos, particularmente no mundo anglo-saxão, um importante debate ${ }^{3}$ : deve-se recusar a Nietzsche o estatuto de pensador político ${ }^{4}$, como ele próprio parece nos incitar, e porque ele não propõe, nesta matéria, nenhuma teoria e nenhum programa adequados? Ou, ao contrário, é possível discernir em seus escritos teses, até mesmo “idéias" especificamente políticas?

Nós pretendemos aqui demonstrar que a simples alternativa entre uma reflexão "política" e, ao contrário, uma reflexão "apolítica" não é suficiente para dar conta da especificidade da posição nietzschiana neste tema, e isso porque Nietzsche repensa de novo, no contexto de sua "nova linguagem", o sentido e o estatuto daquilo que é usualmente pensado sob o nome de "política". Ao recusar a autonomia da esfera política, que ele pensa na perspectiva da cultura, ou seja, dos valores, e, assim, em última análise, também na perspectiva do corpo e da fisiologia, Nietzsche é conduzido a afirmar, por um lado, o seu caráter de sintoma significante e, por outro lado, o seu estatuto de meio ou de instrumento de transformação do homem e da cultura. A evidência do novo estatuto da política, no contexto de uma filosofia da cultura e, de modo correlativo, do corpo, deve permitir compreender, para finalizar, que a ausência de uma teoria política suficientemente determinada não é absolutamente uma lacuna, uma deficiência voluntária da filosofia

3 Cf. SIEMENS, H. Nietzsche's Political Philosophy. A Review of Recent Literature. NietzscheStudien 30, 2001. p. 509-526.

4 Cf., por exemplo, LEITER B. Nietzsche on Morality. London: Routledge, 2002. p.296; BROBJER, T. The Absence of Political Ideals in Nietzsche's Writings. Nietzsche Studien, 27, 1998. p. 300-318.

5 Cf., por exemplo, Ansell-Pearson, K. An Introduction to Nietzsche as Political Thinker. Cambridge: Cambridge University Press, 1994.; CONWAY, D. W. Nietzsche \& the Political. London: Routledge, 1997. 
de Nietzsche: pois ela se esforça precisamente em demonstrar nesse contexto que uma ausência [un délai] é necessária, e que não é ainda possível pretender propor uma nova organização ou uma constituição política precisa, sob pena de permitir uma falta de rigor filosófico, mais precisamente uma precipitação ilegítima que se revelaria perigosa ou vã. Para o filósofo extemporâneo, o tempo não é mais da política tal como pensada usualmente, e muito superficialmente, até agora; e ainda não veio o tempo de se colocar propriamente em discussão um novo projeto político - isto é, de conseguir determinar plenamente o conteúdo daquilo que Nietzsche passa a designar sob o nome de "grande política". Ver-se-á que é precisamente ela que permite compreender por que a filosofia nietzschiana pode ser caracterizada como uma filosofia "antipolítica" em vez de "apolítica".

A política como epifenômeno...

É necessário começar por avaliar a amplitude da dificuldade: numerosos elementos podem, de fato, levar o leitor a considerar que não há reflexão "política" em Nietzsche. Isso parece, em primeiro lugar, efetivamente, provar uma maneira de desprezo pela "política", e em dois sentidos distintos. Alguns textos, antes de mais nada, rejeitam ou zombam da atenção que o homem moderno presta aos "acontecimentos políticos", atenção que é denunciada como "o espírito - e a ausência de espírito - da atualidade e dos jornais", que vem daquilo que os homens imaginam indevidamente - diz Nietzsche -, que tais acontecimentos podem verdadeiramente transformar o estado da humanidade:

Toda filosofia que crê que um acontecimento político possa afastar, ou mais, resolver, o problema da existência é uma brincadeira de filosofia, uma pseudofilosofia. Desde que o mundo existe, frequentemente se 
viu fundar Estados; essa é uma velharia [eins altes Stück] $]^{6}$. Como uma inovação política bastaria para fazer dos homens, uma vez por todas, os felizes habitantes da terra? (SE/Co. Ext. III 4, KSA 1.365).

Nietzsche denuncia aqui o caráter efêmero, e sobretudo superficial, que se revela da esfera política: os pretensos "acontecimentos" políticos são sempre o prolongamento de uma "velharia", e as pretensas "inovações" políticas são sempre repetições. A vontade de reformar o Estado, ou de fundá-lo de novo, deixa intacta a crença no valor da própria noção de Estado e também de seus correlatos: o privilégio concedido à comunidade e à idéia de bem comum, a exigência de os proteger a todo custo contra as irrupções do interesse individual, ou do estrangeiro. Ora, se é verdade que o filósofo genuíno, que distingue antes de mais nada a independência, a liberdade do espírito, não deve se acomodar sobre as crenças e os preconceitos inquestionados, ele não pode, consequentemente, preocupar-se verdadeiramente com esses pretensos "acontecimentos", que, em resumo, não os são, na medida em que eles sempre deixam perdurar crenças fundamentais que há muito tempo informam a vida humana. A exigência de um questionamento radical que se impõe ao filósofo o conduz necessariamente a evitar a consideração superficial desses pretensos "acontecimentos" políticos: "aquele que tem o furor philosophicus no corpo não terá absolutamente tempo para o furor politicus e se absterá sabiamente de ler os jornais todo dia ou mais ainda de servir um partido" (SE/ Co. Ext. III 7, KSA 1.409). Em contrapartida, compreende-se por que os Estados geralmente não cessam de desconfiar dos filósofos genuínos e de tratá-los como inimigos, e por que eles favorecem apenas os pseudofilósofos, cuja reflexão nunca coloca em causa os valores sobre os quais eles mesmos se apóiam (Ibidem, 8, KSA

6 A tradução francesa utilizada pela autora traduziu "altes Stück" por "vieille histoire”. Para evitar mal-entendidos com o termo "história", preferimos utilizar um sentido encontrado nos dicionários e que nos parece ser mais adequado: "velharia" (NT). 
1.411-427 $)^{7}$. A exigência de independência e de radicalidade que se impõe ao pensador genuíno tem, dessa forma, por consequência a exigência - afirmada por Nietzsche de modo reiterado ao longo de toda sua obra - de uma tomada de distância em relação à esfera política: os filósofos genuínos deveriam "abster-se da política e [...] permanecer um pouco afastados", desconfiar dos modos de pensamento muito estreitos que sempre são pressupostos pela reflexão política (MA I/HH I 438, KSA 2.285-286) política, às vezes denunciada por Nietzsche como um "fervor político", até mesmo como a "doença européia que bestializa" (JGB/ BM 241, KSA 5.180), só pode ser para os filósofos genuínos um "desperdício do espírito" (M/A 179, KSA 3.157-158)9 , ou seja, um divertimento - no sentido pascaliano do termo - em relação à sua tarefa própria. Ao filósofo de espírito livre deve necessariamente se impor este mandamento: "tu não farás política" (Nachlass/FP 19 [77] outubro-dezembro de 1876, KSA 8.348), e isso embora, ou melhor, porque sua visada própria diz respeito ao "futuro da humanidade" (Ibidem, 19 [78], KSA 8.348), a qual não permite refletir nem inflectir verdadeiramente o pensamento e a ação políticos.

É claro que a reflexão política não é somente reflexão sobre os eventos. Porém Nietzsche realmente não poupa a filosofia e as teorias políticas ou sociológicas, na medida em que elas já estão, a seus olhos, bastante formadas pelos preconceitos não percebidos, eles próprios resultantes dos afetos e das necessidades fisiológicas mais profundos, os quais nunca são suficientemente interrogados. As teorias políticas, embora pretendam um maior rigor e

7 Cf. também MA I/HH I 469, KSA 2.301: "Quando eles se tornam homens políticos, atribuise comumente aos sábios, quer eles queiram ou não, o papel cômico de ser a boa consciência de uma política."

8 Cf. também M/A § 177, KSA 3.156 e FW/GC 174, KSA 3.500: "Afastado."

9 Segundo o parágrafo 201 da mesma obra, KSA 3.176, "parece cada dia mais claro que é indecente se meter com política". O parágrafo 31 de Gaia ciência, KSA 3.403, entende igualmente que a política pode ser considerada como vulgar e indica, em relação aos indivíduos mais nobres, como uma "prostituição do espírito". 
profundidade, são apenas fenômenos de superfície, "consequências" que nunca percebem suficientemente seu próprio "fundo":

Todas nossas teorias políticas e constituições estatais, sem excluir de modo nenhum o "Reich alemão", são decorrências, decorrências necessárias do declínio; o efeito inconsciente da décadence tornou-se senhor até nos ideais de ciências particulares. Minha objeção contra a inteira sociologia na Inglaterra e França continua a ser que ela só conhece por experiência formações sociais de caducidade e na mais perfeita inocência toma seus próprios instintos de caducidade como norma do juízo-de-valor sociológico. A vida declinante, a diminuição de toda força organizadora, isto é, que separa, que rasga abismos, que subordina e sobreordena, formula-se na sociedade de hoje em ideal... (GD/CI, Streizfüge eines Unzeitgemässen, 37, KSA 6.138) ${ }^{10}$

As teorias políticas ou sociológicas são já expressão da "décadence", de um estado de fraqueza fisiológica que força a considerar certos valores provenientes delas próprias, isto é, certas condições de vida fundamentais. Elas pretendem refletir e impor normas novas, sem perceber que estas se impõem antes a elas mesmas. As teorias que se apresentam como puramente intelectuais e desinteressadas são, na verdade, informadas pelas necessidades próprias de um estado de fraqueza ou doença mais profunda, como indica também, de modo geral, A genealogia da moral: "A idiossincrasia democrática contra tudo que domina e quer dominar, o moderno misarquismo (para formar uma palavra ruim para uma coisa ruim) , pouco a pouco se transpôs e se travestiu em tal medida em espiritual, espiritualíssimo, que hoje, passo a passo, já penetra, já pode penetrar nas mais rigorosas, aparentemente mais objetivas das ciências" (GM/GM II 12, KSA 5.315) ${ }^{11}$. Vê-se que, por exemplo,

10 Tradução conforme Rubens R. Torres Filho. In: NIETZSCHE, F. Obras Incompletas. São Paulo: Abril Cultural, 1978 (Coleção "Os pensadores"), p. 340 (NT).

11 Tradução conforme Rubens R. Torres Filho, Ibidem, p. 308 (NT). 
para além das diferenças e dos conflitos doutrinários, os pensadores políticos não percebem - ou não percebem mais - que suas várias teorias apóiam de fato sempre em pressupostos, e mais fundamentalmente em necessidades idênticas. Toda teoria política e, realmente, a própria noção de política apóia em um privilégio da comunidade em detrimento dos indivíduos que a constituem, o cuidado do todo deve prevalecer sobre aquele de suas partes. Desde Platão, o cuidado político é cuidado do bem comum, ao qual deve se submeter todo interesse particular. Ao mesmo tempo e inversamente, a comunidade é pensada como uma comunidade particular, distinta das outras, mesmo oposta, das quais deve se defender em um cuidado permanente de proteção e conservação. Ora, Nietzsche procura mostrar que esses pressupostos não são evidentes, e que, além disso, eles contém certos perigos: por que pressupor, com efeito, que o "maior número" tem mais valor que o particular, e mais ainda: que a exceção? Por que, antes de tudo, querer privilegiar a satisfação do "todo", e, consequentemente, negligenciar dar atenção aos indivíduos "superior(es), mais potente(s), mais complexo(s), mais fecundo(s)", aos "gênios criadores", que, entretanto, seriam suscetíveis de desempenhar um papel "redentor" em relação ao próprio todo (SE/Co. Ext. III 6, KSA 1.383-404) - de modo que esse privilégio muito prontamente concedido à comunidade parece, a longo prazo, dever ser mais prejudicial que benéfico? Essas preferências fundamentais que orientam permanentemente as formas clássicas da reflexão política surgem, de um lado, como efeito de uma necessidade de simplificação - pois é mais fácil pensar a pretensa uniformidade do todo que a singularidade dos indivíduos; por outro lado, como resultado de uma necessidade de proteção da massa dos indivíduos mais fracos, que, ao sobrevalorizar o todo e preconizar geralmente, ao mesmo tempo, a igualdade dos indivíduos, são providos do meio de se proteger dos indivíduos mais bem dotados e mais potentes, mesmo de erradicá-los pouco a pouco - ao exigir, enfim, a abolição de toda singularidade, de toda exceção, de tudo que há de mais individual no homem: 
Parece agora que faz bem a todos ouvir dizer que a sociedade está em vias de adaptar o indivíduo às necessidades gerais e que a felicidade $e$ a o mesmo tempo o sacrifício do indivíduo consistem em sentir-se como um membro e instrumento útil do todo; [...] Não se quer nada menos quer se confesse ou não - do que uma transformação radical, e mesmo enfraquecimento e supressão do indivíduo: não se cansam de enumerar e acusar tudo que há de mal e hostil, de perdulário, de dispendioso, de luxuoso, na forma que se teve até agora a existência individual, esperam dispor de uma economia mais barata, menos perigosa, mais equilibrada, mais uniforme, quando só houver ainda grandes corpos $e$ seus membros (M/A 132, KSA 3.124) ${ }^{12}$.

Mas se é verdade que o enfraquecimento progressivo dos indivíduos por meio de sua uniformização só pode ter como consequência o enfraquecimento do todo, é preciso dizer, desse modo, que a tradicional exigência política relativa ao bem comum contém uma contradição interna, denunciada nitidamente no parágrafo 43 de Além de bem e mal: "Bem' não é mais bem quando é o vizinho que a tem na boca. E, desse modo, como poderia haver um 'bem comum'?! A palavra contradiz a si própria: o que pode ser comum sempre tem pouco valor." É nesse contexto, entre outros, que é necessário entender a crítica nietzschiana ao Estado considerado como um fim em si, que "não cessa de sacrificar um grande número de talentos superiores no ‘altar da pátria' ou da 'ambição nacional” (MA I/ HH I 481, KSA 2.315). Por essa mesma razão, é necessário, afirma Nietzsche muitas vezes, "O mínimo de Estado possível" (MAI/HHI 473, KSA 2.308; M/A 179, KSA 3.157, e Nachlass/FP 18806 [377], KSA 9.294). Ou, no mínimo, é necessário compreender que:

12 A crítica da sobrevalorização do bem comum está relacionada com a crítica da desvalorização do egoísmo e de seu correlato, a valorização do altruísmo e do sacrifício de si, o que constitui o que Nietzsche denuncia sob o nome de "instinto gregário" ou de "instinto de rebanho". Cf., por exemplo, M/A 46 -147, KSA 3.137-139, e FW/GC 328, KSA 3.555-556. Tradução conforme Rubens R. Torres Filho, Ibidem, p. 172-173 (NT).

50 | cadernos Nietzsche 32, 2013 
"A finalidade do Estado jamais deve ser o Estado, mas sempre os indivíduos" (Nachlass 187617 [17], KSA 8.299) ${ }^{13}$.

$\mathrm{O}$ conjunto dessas proposições parece realmente indicar a rejeição nietzschiana de toda reflexão política: se o cuidado da polis, da comunidade, deve eclipsar-se ante o cuidado do individual, e se as teorias e as vontades políticas são apenas a expressão superficial de valores e de necessidades mais fundamentais que elas, a esfera política não se veria privada de todo interesse, e mesmo de toda consistência? O caráter "antipolítico" da reflexão nietzschiana deveria, desse modo, ser considerada rejeição do político, que acaba necessariamente em um "apolitismo", em um abandono radical do cuidado político em favor do único cuidado do "indivíduo antipolítico que busca aperfeiçoar-se, à margem do mundo moderno", segundo a fórmula de W. Kaufmann ${ }^{14}$.

... e como sintoma: da política à "questão fundamental" da cultura

Entretanto é necessário notar que, se a esfera da política é repensada por Nietzsche como um epifenômeno, como um fenômeno de superfície ${ }^{15} \mathrm{em}$ relação aos valores e às necessidades que subjazem a ela, não é menos verdade que essa esfera é, ao mesmo tempo, pensada como um dos sintomas significantes que permitem precisamente discernir esses mesmos valores e necessidades - e como um sintoma ao qual Nietzsche atribui, em certos textos, uma importância primordial. Os juízos políticos, frequentemente

13 Cf. Nachlass 30 [8] outono 1873-inverno 1873-1874, KSA 7.733: "a finalidade do Estado é a humanidade nobre, ela reside fora dele, o Estado é apenas um meio".

14 Kaufmann, W.A. Nietzsche. Philosopher, Psychologist, Antichrist. Princeton: Princeton University Press, 1974. p. 418.

15 Sabe-se, por outro lado, que Nietzsche critica a falta de rigor de um pensamento que não presta atenção “à superfície, à pele” (FW/GC Prefácio, KSA 3.351-352), e que pretende uma imediata e excessiva "profundidade" (cf., por exemplo, WS/AS § 17, KSA 2.551-553: "Explicações profundas"). 
Denat, C.

estreitamente associados aos juízos morais, são de fato por vezes apresentados por Nietzsche como mais fundamentais que os juízos de ordem teórica: segundo um póstumo de 1885, os “juízos de valor lógico" podem ser reduzidos "a juízos morais e políticos" (Nachass/FP outono 1885 - outono 18862 [78], KSA 12.98). Muito distante de dever se afastar absolutamente destes últimos, o filósofo-médico, desse modo, ao contrário, deve prestar atenção neles enquanto sintomas significantes de um certo tipo de homem e cultura: é necessário de fato "Examinar todas as coisas quanto a seu valor para conhecê-las, por exemplo, a arte, as circunstâncias políticas, etc." (Nachlass/FP primavera - verão 188111 [64], KSA 9.466), é necessário poder, em outras palavras, "fazer uma apanhado dos instintos fundamentais de nosso movimento político, intelectual e social na Europa." (Nachlass/FP outono 1885 - outono 18862 [179], KSA 12.155). E, assim, se é verdade que, por sua capacidade de colocar em questão os valores sobre os quais sua comunidade se funda, o filósofo é figura de exceção, essa mesma coragem implica, entretanto, que ele não se exclua absolutamente dessa mesma comunidade, que ele deva ter relações com ela para melhor lhe interrogar, assim como indica claramente, por exemplo, o parágrafo 26 de Para além de bem e mal, KSA 5.44: o homem "fora do comum", que "aspira instintivamente à sua cidadela e ao seu retiro secreto onde ele esteja livre da multidão, do grande número, da maioria, onde ele possa esquecer-se da regra 'homem', ele que é exceção a ela", deve, entretanto, "dirigir-se ao baixo, e sobretudo 'ao interior'."... Da mesma forma que o médico não poderia cumprir sua obra se ele fugisse de seus doentes e da doença, o filósofo deve estabelecer relação com aquilo mesmo que ele pretende colocar em questão para avaliar. Se ele deve estar em certo sentido "afastado" da esfera política, isto é, não estar submetido, como o grande número, aos valores que ela pressupõe, esse "afastamento" só pode ser relativo: ele deve ser 
a condição de possibilidade do questionamento filosófico, e não o esquecimento e a rejeição absoluta do que está em questão ${ }^{16}$.

Ora, o que revela esse questionamento com respeito à esfera e às circunstâncias políticas, enquanto sintomas? Não que necessariamente toda política seja sem valor, mas que a política tal como geralmente ela foi pensada e praticada até aqui é um sintoma de decadência ${ }^{17}$. A supervalorização do estado, a dominação tanto das "idéias modernas" quanto dos "ideais democráticos" que são exigências da igualdade contra toda idéia de "privilégio" ou de "direitos" particulares, o valor atribuído à compaixão, ao altruísmo contra todo egoísmo, contribuem para fazer do homem um "animal de rebanho" (JGB/BM 202, KSA 5.124-126). O "movimento democrático" que domina a Europa pode assim ser considerado: "não somente uma forma de decadência da organização política, mas uma forma de decadência, isto é, de diminuição do homem, de sua mediocrização e de rebaixamento de seu valor [...]" (JGB/BM 203, KSA 5.126, grifo nosso).

A "decadência da organização política" é o sintoma de um movimento de decadência mais fundamental: de uma decadência do próprio homem. Ora, aqui, como em toda doença, o tratamento e a modificação do sintoma não seria suficiente para tratar o mal. O filósofo enquanto espírito livre deve colocar mais radicalmente a questão, e buscar modificar o que é a fonte do sintoma, ou seja, o tipo de necessidades e de valores que subjazem a ele - os pretensos "ideais" políticos novos, sem o saber, apenas prolongaram os "valores eternos" que conduziram à decadência do homem (Ibidem). Assim, a esfera política não deve ser mais considerada como uma esfera autônoma, que tem por ela e nela mesma um sentido,

16 Para um aprofundamento desse ponto, ver nosso artigo: "Ne pas rester lié à sa propre rupture". Solitude et communauté dans la philosophie de Nietzsche. Phaenex, v. 6, n. 2, Automne/Hiver 2011. p. 29-70, p. 46-55. Site: http://www.phaenex.uwindsor.ca/ojs/leddy/ index.php/phaenex/article/view/3478/2717.

17 Cf. GD/CI Streizfüge eines Unzeitgemässen § 37, KSA 6.136-139, citado supra. 
e como uma potência de transformação do homem. Ela deve ser apenas considerada como um signo que permite avaliar o conjunto dos valores fundamentais que constituem o que Nietzsche designa um "complexo de cultura". Em outras palavras, ela deve apenas ser um dos meios de colocar, enfim, o que constitui aos olhos de Nietzsche "a questão fundamental" que é a questão da "cultura" (GD/ CI, Was den Deutschen abgeht, 4, KSA 6.106).

É precisamente a ignorância desse estatuto apenas sintomático da política, e é precisamente a consideração do domínio político como possuindo um sentido e um valor em si que conduzem a esse "desperdício do espírito" que Nietzsche denuncia regularmente, pois a inteligência e a força que são despendidas nas questões e nas tentativas de modificação apenas superficiais são de fato perdidas para a tarefa mais fundamental que deveria ser aquela do filósofo. E é por isso que numerosos textos indicam efetivamente que o desenvolvimento da cultura é necessariamente inversamente proporcional ao desenvolvimento do cuidado político tal como usualmente entendido - dificuldade que, segundo Nietzsche, torna-se particularmente manifesto no caso da Alemanha:

Se se despende para o poder, para a grande política, para a economia, o comércio mundial, o parlamentarismo, os interesses militares, — se se dissipa desse lado o quantum de entendimento, de seriedade, de vontade, de autossuperação que existe, ele fará falta do outro lado. A cultura e o Estado - não se deve ter ilusões sobre esse ponto - são antagonistas: “o Estado-cultura" é apenas uma idéia moderna. Um vive às custas do outro, um prospera a expensas do outro. Todas as grandes épocas da cultura são épocas de declínio político: o que é grande no sentido da cultura é apolítico, mesmo antipolítico. (Ibidem, 4, KSA 6.106) ${ }^{18}$.

18 Cf. também Ibidem 1, KSA 6.106: "a política devora toda a seriedade devida às coisas efetivamente espirituais".

54 | cadernos Nietzsche 32, 2013 
O cuidado dos interesses do Estado, a busca do "poder" estatal e nacional, o dispêndio das forças coletivas e individuais a favor de uma "grande política", entendida aqui no sentido da Machtpolitik de Bismarck, desviam uma vez mais da questão mais fundamental da cultura e dos valores. Por essa razão, como indica ainda um póstumo da mesma época, "Todas as grandes épocas da cultura foram, politicamente, épocas pobres" (Nachlass/FP setembro de 188819 [11], KSA 13.547). E é possível dizer, por outro lado, como faz Nietzsche desde a época de Humano, demasiado humano, que "A cultura deve seus valores mais elevados a seus períodos de fraqueza política" (MA I/HH I 465, KSA 2.300) ${ }^{19}$. Quem pretende contribuir com o florescimento da cultura não deve se prestar a uma reflexão nem a uma atividade políticas: ele deve, nesse sentido, ser "apolítico". Ele deve mesmo ser capaz de resistir, mesmo se opor ao fervor político que é, em primeiro lugar, um dos sintomas nos quais ele lê a decadência de sua cultura: assim, ele deve ser mais precisamente um indivíduo "antipolítico".

Todavia, o exame de um outro caso, ao mesmo tempo mais complexo e mais favorável, leva a nuançar o diagnóstico e a exigência terapêutica. $\mathrm{O}$ que ocorre é que, no contexto de uma cultura suficientemente saudável, o perigo constituído pela política decresce. $\mathrm{Na}$ Antiguidade grega, de fato, os valores fundamentais favoreciam um grau de saúde suficientemente elevado para que o desperdício de forças requerido pela esfera política pudesse fazer mal - e, em última análise, essa esfera é posta ao serviço do florescimento da cultura e da saúde dos indivíduos:

A polis grega, como toda potência política organizadora, era exclusiva e desconfiada contra o crescimento da cultura [...]. Ela não queria

19 Cf. também MA I/HH I $§ 481$, KSA 2.315: “[...] o florescimento político de um povo provoca quase necessariamente um empobrecimento, um esgotamento da inteligência, uma diminuição da potência criativa para obras que exigem muita concentração e atenção exclusivas". 
admitir nenhuma história, nenhum vir-a-ser da cultura; a educação estabelecida na lei estatal devia obrigar todas as gerações e firmá-las em um nível. Não era outra coisa o que mais tarde queria Platão para seu Estado ideal. Foi a despeito da polis, portanto, que se desenvolveu a cultura; indiretamente, sem dúvida, e contra a vontade, ela auxiliou, porque a ambição do indivíduo, na polis, era estimulada ao máximo, de tal modo que ele, uma vez na trilha da formação do espírito, prosseguia nela até o último extremo. (MA I/HH I 474, KSA 2.308) ${ }^{20}$.

Vê-se bem aqui se confirmar que $a$ política, que toda política não é ela própria o problema - que ela não é um em-si, mas antes um sintoma, cujo sentido e valor mudam com aquilo do qual ela é sintoma: quando os valores fundamentais da cultura não favorecem imediatamente a igualdade, a mediocrização, o enfraquecimento do homem, a atividade política toma um aspecto específico - favorecendo, por exemplo, a luta e a autossuperação dos indivíduos - e acabando por fornecer uma "ajuda indireta" à cultura.

Ao contrário, o problema que afronta a Europa moderna é, sobretudo, um problema cultural, que é também um problema axiológico e físio-psicológico. Não são, com efeito, nossas "instituições" que são problemáticas, mas antes as necessidades e os instintos - o estado doentio, de decadência fisiológica - que são suas fontes, como afirma Nietzsche com vigor em um aforismo, essencial para nosso propósito, do Crepúsculo dos ídolos:

Crítica da modernidade. - Nossas instituições não valem mais nada: isso é reconhecido unanimemente. Só que isso não se refere a elas, mas, ao contrário, a nós. Depois que perdemos todos os instintos dos quais provém as instituições, nós perdemos as próprias instituições, porque nós não temos mais valor para elas. [...] Todo o ocidente não

20 Cf. também a versão preparatória desse texto: Nachlass/FP 5 [197] primavera - verão 1875, KSA 8.95-96. NT: Tradução conforme Rubens R. Torres Filho. In: NIETZSCHE, F., ibidem, p. 116 (modificada).

56 | cadernos Nietzsche 32, 2013 
tem mais esses instintos dos quais se desenvolvem as instituições, a partir dos quais se desenvolve o amanhã [...] (GD/CI, Streizfüge eines Unzeitgemässen, 39, KSA 6.140-141).

Da "pequena" à "grande política"

Assim, compreende-se melhor porque de fato Nietzsche não propõe um novo projeto, uma nova constituição política: no contexto de uma cultura mórbida, niilista, cujos instintos levam ao seu final, seria totalmente vão contentar-se em propor uma modificação do fenômeno de superfície e do sintoma que é a organização política. O problema que deve ser resolvido é mais profundo, ele refere-se aos nossos instintos, a nosso estado fisiológico: "Todos nós não somos mais material para uma sociedade: eis uma verdade que é tempo de proclamar!" (FW/GC 356, KSA 3.597). A reforma da cultura, e, consequentemente, também da esfera política, implica fazer desta um passo atrás - ou, para retomar uma metáfora cara a Nietzsche, cavar mais fundo, de se fazer "toupeira"21, a fim de tratar o mal e não somente o sintoma, a fim de não ceder, em outras palavras, à precipitação que faz com que, geralmente, as teorias políticas renovem os problemas existentes ao invés de os resolver. Somos nós mesmos - os homens que é necessário transformar, se se quer poder transformar também suas instituições, seus modos de organização políticas. Nesta perspectiva, Nietzsche substitui em parte o cuidado político tradicional por um cuidado educativo, repensado como exigência de "elevar" o homem, ou seja,

21 Cf. M/A Prefácio, KSA 3.11, e WS/AS 229, KSA 2.657: “Os enterrados. — Nós nos escondemos em segredo; entretanto, não em razão de algum desgosto pessoal, como nossa insatisfação das condições políticas e sociais do presente, mas porque nós queremos, com nosso ocultamento, poupar e acumular forças das quais a cultura terá mais tarde absolutamente necessidade [...]." 
de modificar profundamente a totalidade fisio-psicológica que é o homem, de modo a favorecer o aparecimento de novos valores.

É, portanto, legítimo dizer que o cuidado político é radicalmente abandonado por Nietzsche em favor de um cuidado cultural, axiológico e individual? Isto não é, sem dúvida, o propósito do próprio Nietzsche, que nos indica, em contrapartida, que, ao levar a superficialidade do questionamento político habitual à esfera da cultura e dos valores, ele pretende precisamente não renunciar à política, mas antes repensar radicalmente o sentido da política, de modo que ela pudesse atingir efetivamente o alvo que ela até aqui fixou em vão: transformar a existência humana enquanto existência comum e não somente individual. É necessário ver bem que, de fato, Nietzsche não nos convida somente a uma reflexão extra- ou infra-política (relativa aos indivíduos), mas também, ao mesmo tempo, a uma extensão da reflexão política mesma, até aqui indevidamente limitada pelas perspectivas estatais e nacionalistas, e pelas aspirações de curto prazo (interesses econômicos, militares, etc.). Por essa razão, ele critica efetivamente a política tal como pensada usualmente, como uma "pequena política", cuja forma mais manifesta (e igualmente a seus olhos a mais perigosa) é, no fim do século XIX, a política nacionalista, que permanece encerrada nas perspectivas mais estreitas e mais superficiais, e que atua, assim, contra o desenvolvimento da própria cultura. Nietzsche denuncia com a maior virulência essa tendência, sobretudo no caso da Alemanha ${ }^{22}$, mas geralmente também na Europa, como: " essa doença e essa desrazão mais contrária à cultura que possa existir, essa névrose nationale da qual a Europa está doente, essa perpetuação

22 Cf. M/A 190, KSA 3.162-163: "Quando os alemães tornaram-se interessantes para os outros povos da Europa [...], isso ocorreu devido a uma cultura que eles não possuem mais hoje, da qual eles se aliviaram com fúria cega, como se tratasse de uma doença: e, entretanto, não imaginaram nada melhor para a substituir que o absurdo político e nacional". 
da pulverização de Estados na Europa, [...] a pequena política [que levou] a Europa a um impasse" (EH/EH, Warum ich so gute Bücher schreibe, Der Fall Wagner, 2, KSA 6.360 ${ }^{23}$.

Ora, para lutar contra essa "doença", Nietzsche não requer somente que se pense um aquém da comunidade política, mas ele nos convida, pelo contrário, a refletir um além, ou, dizendo mais precisamente, uma extensão da comunidade estatal e nacional: se é preciso, por um lado, pensar menos que o Estado (os indivíduos, sua hierarquia), é preciso também pensar mais que o Estado, a saber, a Europa, essa comunidade que compartilha valores (platônicos e cristãos) idênticos, e em relação aos quais as distinções entre nações são apenas superficiais. Por essa razão, o filósofo de espírito livre, que certamente não deve "permanecer ligado a uma pátria" (JGB/BM § 41, KSA 5.59), deve também ser pensado sob a figura e o nome de "bom europeu", cuja tarefa deve consistir em "trabalhar pela fusão das nações" (MA I/HH I 475, KSA 2.309-311), à "re-ligar os povos" (EH/EH, Warum ich so gute Bücher schreibe, Der Fall Wagner 2, KSA 6.360) ${ }^{24}$.

Nietzsche não pretende, consequentemente, renunciar a toda forma de política. Mas, contra as insuficiências e os perigos da "pequena política", que por seu caráter ao mesmo tempo superficial e limitado produz obstáculos às questões e às tarefas mais fundamentais, Nietzsche requer o surgimento de uma "grande política" (JGB/BM 208, KSA 5.137-140), ou, em outros termos ainda, de uma "política superior" capaz de refletir, e eventualmente de modificar, a dimensão subterrânea (instintiva, pulsional) que subjaz às ações e ao vir-a-ser do homem (GD/CI Die vier grossen Irrthümer 2, KSA 6.89-90). Ao evocar a necessidade de uma "grande política",

23 Sobre a fórmula "pequena política", cf. também FW/GC 377, KSA 3.628-631, e JGB/BM 208, KSA 5.137-140.

24 Cf. também sobre essa idéia: MA I/HH I 475, KSA 2.309-311. Sobre as noções de "bom europeu" e de "Europa", cf. os verbetes correspondentes em DENAT, C.; WOTLING, P. Dictionnaire Nietzsche. Paris: Ellipses, 2013, p. 54-59. 
Nietzsche retoma, invertendo ironicamente o sentido, uma fórmula que, em sua época, caracteriza a política de Bismarck ${ }^{25}$ - exemplo típico de uma política nacionalista e muito míope, na realidade, exemplo típico de uma "pequena política" que Nietzsche não cansa de criticar e de zombar, e cuja denominação mostra-se usurpada ${ }^{26}$. Ao qualificar a "política" como "grande política", Nietzsche pretende sobretudo propor um sentido radicalmente novo - em consequência de sua inserção em problemáticas novas que são as suas - dessa noção ${ }^{27}$. Mas o que recobrem precisamente essa noção e essa exigência? Um texto póstumo de janeiro de 1889 indica-nos as características principais que decorrem das críticas desenvolvidas anteriormente: a "grande política" deve se dedicar, enfim, às questões fundamentais, as quais a "pequena política" sempre nos desvia - ela deve permitir, enfim, tentar a oposição "à degeneração e à confusão dos instintos" que caracteriza a época moderna, e o interesse pelas "questões mais imediatamente importantes: aquelas da alimentação, do vestuário, da dieta, da saúde, da procriação". Em outras palavras, ela faria "fisiologia", a "rainha de todas as outras questões", a fim de poder lutar "contra tudo que há de degenerado e de parasitário na vida". Ela teria em vista, para além das distinções entre nações e povos, um fim e um "todo superior", uma vez que se trata de "elevar a humanidade" inteira (Nachlass/ FP dezembro 1888 - início janeiro 188925 [1], KSA 13.637-638).

25 As primeiras ocorrências da noção de "grande política", no primeiro volume de Humano, demasiado humano (§ 481, KSA 2.314-316) e em Aurora (189, KSA 3.161-162), remetem muito mais a seu sentido usual que ao uso propriamente nietzschiano da fórmula "grande política". Cf. ainda Nachlass/FP 19 [1] setembro de 1888, KSA 13.540: "[Os alemães] tornaram-se maçantes, talvez eles já o fossem, a grande política devora a seriedade para todas as coisas efetivamente grandes".

26 Cf., em particular sobre essa idéia, JGB/BM § 241, KSA 5.180-182.

27 É necessário notar que essa é uma estratégia linguística recorrente nos textos nietzschianos: ao adicionar em um termo usual ou uma noção clássica os epítetos "grande" ou "superior(a)", Nietzsche pretende, geralmente, propor uma concepção radicalmente nova desse termo ou dessa noção (por exemplo, "grande amor", "piedade superior", "grande sofrimento", etc.).

60 | cadernos Nietzsche 32, 2013 
Percebe-se que a "grande política", ela própria, não corresponde a um "programa" exatamente determinado: se Nietzsche indica de modo geral qual tipo de questões e de exigências devem ser pensadas, ele não determina a natureza precisa dessas exigências - de modo que acabamos encontrando novamente uma das dificuldades iniciais.

É neste ponto, entretanto, que se torna possível entender as razões e, sobretudo, a necessidade dessa relativa indeterminação: como indica, com efeito, o mesmo fragmento póstumo: é ainda necessário "criar um partido da vida, suficientemente forte para a grande política". Com efeito, os indivíduos susceptíveis de pensar, de implementar, de tentar uma grande política ainda não existem: "Procura-se em vão em nossos dias, e sem dúvida durante muito tempo ainda, os homens capazes dessas criações grandiosas, os grandes homens propriamente, tais como eu os compreendo; eles estão em falta" (Nachlass/FP junho - julho de 188537 [8], KSA 11.581). O surgimento e a determinação mais precisa da grande política requerem ainda que sejam cultivados [élevés] os homens capazes de a encarnar. Isso porque ela só pode, nesse instante da história, ser esboçada em suas linhas gerais, enquanto que exigência do espírito livre que soube compreender as deficiências de sua época e da "pequena política", mas que se encontra, entretanto, em face dessa constatação:

no presente, a força construtiva está paralisada; a coragem de fazer planos a longo termo está desestimulada; os gênios organizadores começam faltar: - quem ousa ainda empreender obras que, para seu cumprimento, é necessário contar com milênios? Vê-se morrer precisamente a crença fundamental sobre cuja base alguém pode calcular, prometer, antecipar o amanhã em seu projeto, sacrificá-lo por seu projeto de modo que o homem só tivesse valor, sentido, na medida em que ele fosse uma pedra num grande edifício [...] Em suma — ah, calar-se-á sobre isso por muito tempo ainda! — o que não se construirá mais a partir de agora, não poderá ser mais construído, é — uma sociedade 
na acepção antiga do termo; tudo falta para construir esse edifício, e, primeiramente, o material. Todos nós não somos mais material para uma sociedade: eis uma verdade que é tempo de proclamar! (FW/GC 356, KSA 3.596-597)

Por essa razão, a necessidade de uma "grande política", "a coerção à grande política" (JGB/BM § 208, KSA 5.137-140) podem ser anunciadas, exigidas, mas não ainda plenamente determinadas nem implementadas. $\mathrm{O}$ exame e o diagnóstico relativos ao presente conduzem necessariamente a dever pensar as etapas, as condições prévias de uma autêntica "grande política": antes de poder pensar completamente a possibilidade de uma nova legislação, é necessário inicialmente poder pensar completamente a diversidade e a hierarquia dos valores, como testemunha a história - uma tarefa que Nietzsche certamente começou, mas da qual ele requer que seja continuada e estendida ${ }^{28}$. É necessário, também e sobretudo, poder pensar as condições de possibilidade dos surgimento desses novos homens, desses filósofos e legisladores do amanhã, cuja tarefa será autenticamente criadora e transformadora: o surgimento de uma grande política requer, inicialmente, uma tarefa de educação ou de cultivo [élevage] dos indivíduos, e é necessário também ver que essa dificuldade é, no mínimo, dupla, se é verdade que, neste momento, ainda faltam os educadores verdadeiros - se é verdade que "há necessidade de educadores que sejam eles próprios educados, espíritos superiores, nobres, que sejam provados a todo momento" (GD/CI, Was den Deutschen abgeht, 5, KSA $6.107)^{29}$. Que Nietzsche não nos proponha ainda projeto político, legislação plenamente determinada, não é, de nenhuma maneira, sinal da vaidade de suas propostas nesses temas: é, ao contrário,

28 Cf. sobre isso, por exemplo, a nota final da primeira dissertação de Genealogia da moral. 29 O problema da educação, ou do cultivo [élevage] dos indivíduos superiores, põe um outro problema ligado à questão da duração: "O problema da educação, pois a vida de um indivíduo é muito breve.” (Nachlass/FP 26 [407] verão - outono de 1884, KSA 11.260). 
a consequência da independência, da prudência e do rigor que são requisitos da filosofia, e que se opõe a uma vontade precipitada e muito pouco refletida de oferecer a leitores eles mesmos muito impacientes os resultados que ele não teve tempo ainda de determinar. Desde o prefácio de Sobre o futuro de nossos estabelecimentos de ensino, KSA 1.648, Nietzsche nos previne nestes termos: "O leitor de quem eu espero alguma coisa deve ter três qualidades: ele deve ser calmo e ler sem pressa, [...] ele não deve esperar, enfim, uma tabela de resultados. / Eu vejo certamente vir um tempo em que homens sérios, a serviço de uma cultura inteiramente renovada e purificada e em um trabalho comum, tornar-se-ão novamente os legisladores da educação cotidiana - da educação que leva a essa cultura; é provável que então produzirão tabelas - mas esse tempo está distante! e o que deve ser produzido nesse meio-tempo! [...]."

Aristocracia, democracia e longa duração: as condições da "grande política"

Os requisitos, e mais ainda a formação dos indivíduos superiores, não são uma alternativa ao olhar político, elas são, ao contrário, sua condição de possibilidade. É neste contexto e nesta dupla perspectiva que passa a ter expressamente sentido a exigência "aristocrática" de Nietzsche: desde seus primeiros escritos - e, entre outros, Sobre o futuro de nossos estabelecimentos de ensino, Nietzsche liga estreitamente a exigência de uma recriação da cultura à idéia da "natureza aristocrática do espírito", ou seja, ao cuidado e à hierarquia dos indivíduos, que se opõem ao cuidado democrático uniformizante da "massa". Trata-se, desde essa época, de pensar "uma cultura verdadeira, isto é, aristocrática, fundada sobre uma sábia seleção de espíritos". A noção de aristocracia, em outras palavras, não designa aqui imediatamente um modo de organização política, mas, mais radicalmente, um certo tipo de valores, que induz nos indivíduos e em relação a eles um certo modo de pensamento e de 
comportamento que poderia finalmente se manifestar, entre outros, no campo político: enquanto os valores democráticos ou "plebeus" implicam "hostilidade contra todo privilégio e toda autocracia" (JGB/BM 22, KSA 5.37), os valores nobres provocam, ao contrário, um sentimento de diferença e de distância entre indivíduos que surge como a condição necessária da "elevação do tipo 'homem”, da contínua "autossuperação do homem" (JGB/BM 257, KSA 5.205). O Anticristo opõe firmemente nesse sentido os "valores aristocráticos" aos "valores cristãos" (AC/AC 37, KSA 6.209), a "mentalidade aristocrática" à vontade de igualdade, oriunda do cristianismo e que "se infiltrou até na política" (AC/AC 43, KSA 6.217-218, grifo nosso). A política é aqui, uma vez mais, apenas a expressão de um certo tipo de valores e de cultura mais profundo que ela própria, e cuja modificação somente pode resultar, como consequência, uma modificação das concepções políticas dominantes.

Desse modo, a questão é saber como os valores atualmente dominantes, e que foram incorporados pelos europeus após um muito longo período que fundou sua autoridade, poderiam ser efetivamente substituídos por novos valores. Nietzsche indica, várias vezes, que colocar do avesso [renversement] os valores não pode se constituir uma tarefa a curto prazo, que isso não pode ser o resultado de algo como uma revolução brutal em matéria axiológica: à longa duração que presidiu a assimilação dos valores presentes, deve necessariamente também corresponder um olhar transformador a longo prazo, que leva em conta as necessidades inerentes à lógica da incorporação. Nietzsche rejeita, assim, a tentação de derrubar o Estado, apesar das críticas que ele lhe endereça:

Trabalhar pela difusão e efetivação dessa representação é, sem dúvida, uma outra coisa: é preciso ter uma idéia muito pretensiosa de sua própria razão e entender a história pela metade para desde já por a mão no arado - enquanto ninguém pode ainda indicar as sementes que devem ser posteriormente espalhadas sobre o terreno devastado. Confiemos, pois, na "prudência e egoísmo dos homens", para que, por 
agora, o Estado subsista ainda por um bom tempo e tentativas destruidoras, da parte de semi-sábios exaltados e precipitados, sejam repelidas! (MA I/HH I 472, KSA 2.306-307) ${ }^{30}$.

De modo mais geral, ele opõe ao "charlatanismo" revolucionário, que pretendeu em vão operar uma "modificação importante das apreciações de valor, no domínio da política"31, a exigência de proceder com vagar e "por longos períodos":

Para que uma modificação ocorra com a maior profundidade possível, é necessário administrar o remédio em doses menores, mas incansavelmente e por longos períodos! O que se pode criar de grande de uma só vez! Nós nos guardamos, dessa forma, de trocar, com precipitação e violência, por uma nova apreciação de valor das coisas, o estado da moral que estamos habituados - não, queremos continuar viver por muito tempo nesse estado antigo - até que, provavelmente bem depois, nós tenhamos nos dado conta que a nova apreciação de valor tornou-se, em nós, a potência preponderante e que as pequenas doses, às quais devemos nos habituar desde agora, colocaram em nós uma nova natureza. (M/A 534, KSA 3.305).

Compreende-se, assim, que a filosofia nietzschiana não é uma filosofia imediatamente destrutiva; ao contrário, opondo-se à "precipitação e violência", às perigosas "tentativas destrutivas", Nietzsche pensa antes uma lógica da transformação e da substituição, que esta famosa fórmula de Gaia ciência, entre outras, resume: "É somente enquanto criadores que podemos aniquilar!" (FW/GC 58, KSA 3.422). Porque não se pode "criar nada de grande de uma só vez",

30 NT: Tradução conforme Rubens R. Torres Filho. In: NIETZSCHE, F., ibidem, p. 115.

31 Para um aprofundamento dessa questão, cf. MARTon, S. Nietzsche et la Révolution Française. Remarques sur la devise révolutionnaire. In: DENAT, C.; PIAZZESI, C. Nietzsche, penseur de la politique ? Nietzsche, penseur du social?Pise-Paris: ETS/Editions d'Ariane, 2011. p. 115-127, especialmente p. 124-125. 
Denat, C.

uma lógica da transformação e da lenta re-criação se revela necessária. Ora, uma tal lógica de re-criação não pode se efetivar a partir do nada. Ela implica, ao contrário, ter em conta, inicialmente, as condições e circunstâncias presentes: para que surjam os filósofos legisladores do amanhã, os espíritos livres devem, desde agora, refletir sobre "as condições para o seu surgimento, que deveriam em parte criar, em parte explorar", e, para sua obra de cultivo [élevage], o filósofo deve saber usar também "as condições políticas e econômicas de sua época” (JGB/BM 203 e 61, KSA 5.126-128 e 79-81), e mesmo os valores dos quais elas são a manifestação.

Ora, desse ponto de vista, Nietzsche coloca em evidência um fenômeno paradoxal: a própria autoridade das idéias modernas, dos valores democráticos, que, como foi visto, contribui para "uma igualação e mediocrização do homem", ao mesmo tempo, constitui as condições propícias ao aparecimento de "homens de exceção, que possuem essa qualidade de serem extremamente perigosos e extremamente atraentes", ou, em outras palavras, "uma organização que trabalha involuntariamente no cultivo [élevage] de tiranos, - em todos os sentidos do termo, inclusive no mais espiritual" (JGB/BM 242, KSA 5.183). Que, com efeito, a grande maioria dos homens se encontre reduzido ao estado de "animal de rebanho", pronto a se submeter a uma autoridade e obedecer, isso é o que deve favorecer a possibilidade de imprimir à humanidade uma nova direção: "as possibilidades de adestramento dos homens tornaram-se muito grandes nesta Europa democrática; os homens que aprendem facilmente, a se sujeitar facilmente, são a regra: a besta de rebanho, que pode mesmo ser extremamente inteligente, está preparada. Aquele que pode comandar encontra aqueles que não podem fazer outra coisa que obedecer [...]" (Nachlass/FP verão - outono de 1884 26 [449], KSA 11.270). O projeto de cultivo [élevage] dos indivíduos superiores, de um tipo humano oposto ao tipo democrático, plebeu, decadente, não tem em vista, afinal, o desaparecimento deste último, mas, ao contrário, supõe sua existência: não somente porque um tipo superior só tem sentido e só 
é possível relativamente a outros tipos que lhe são inferiores, mas também porque sua tarefa consistirá, finalmente, em trabalhar para dominar a humanidade a fim de transformá-la. Trata-se de cultivar uma "nova aristocracia", ou seja: "um tipo de homens superiores que, graças à preponderância de sua vontade, de seu saber, de sua riqueza, de sua influência, se servirão da Europa democrática como seu instrumento mais dócil e mais flexível para tomar nas mãos os destinos da terra, para trabalhar enquanto artistas para formar o próprio "homem"' (Nachlass/FP outono de 1885 - outono de 1886 2 [57], KSA 12.87-88 ${ }^{32}$.

Assim, o projeto nietzschiano de uma "grande política" encontra-se, de início, condicionado pela necessidade de cultivar [élever] os homens superiores, ou "nobres", capazes de transformar a humanidade ao invés de reconduzir indefinidamente os valores que são fontes da decadência: razão pela qual o tempo da grande política ainda não chegou. E a própria "grande política" não pode se conceber como uma tarefa de curto prazo: a transformação dos valores, das condições de existência, não pode mais ser pensada como uma tarefa imediata, a curto prazo: ela implica, ao contrário, uma longa duração e a necessidade, para os homens superiores, de avaliar e de "reinar por milênios" (Nachlass/FP primavera de 1884 25 [354], KSA 11.106). Vê-se bem aqui uma modificação radical do sentido da "política". Porque ela é repensada sob a perspectiva da cultura, dos valores, e da longa duração, o indivíduo superior e responsável pela "grande política" não é mais, propriamente falando, um homem de poder, cujo papel consistiria a exercer por pouco tempo sua autoridade sobre os homens do presente. $\mathrm{O}$ homem superior, o homem efetivamente potente, não é um homem de poder,

32 Cf. também Nachlass/FP 2 [13] outono 1885 - outono 1886, KSA 12.73: "Na medida em que na Europa se desenvolve atualmente o tipo 'animal de rebanho', não seria o grande momento de tentar instaurar um adestramento sistemático, artificial e consciente a fim de produzir o tipo oposto e suas virtudes? E não seria, enfim, para o movimento democrático mesmo, uma espécie de alvo, de redenção e de justificação, se acontecer de alguém se servir dele $[\ldots]$ ?.". 
mas um criador de valores, um legislador que não pode ser assimilado à figura do homem político no sentido em que pensamos normalmente, ou à figura tradicional do "Príncipe", como indica o mesmo fragmento póstumo:

— os Principes são de todas as maneiras homens de segundo escalão: os homens efetivamente grandes reinam por milênios e não podem se interessar pelas coisas presentes. Os príncipes são seus instrumentos ou cães astutos que dão eles mesmos a aparência de serem instrumentos. / Mostrar, dominando a imagem do príncipe (como instrumento do sábio), a imagem do sábio supremo. (Nachlass/FP primavera de 1884 25 [354], KSA 11.106) ${ }^{33}$.

Se os filósofos do amanhã devem dominar e comandar, isso deve ocorrer de tal modo que eles não permaneçam dependentes daqueles que eles comandam, não mais que dos valores admitidos - o que é próprio da dominação política usualmente aceita: eles usarão um gênero "mais sutil de dominação", e eles saberão "obter a calma, preservando-se da algazarra e das dificuldades próprias aos modos mais grosseiros de governo, assim como a pureza, preservando-se da sujeira necessária a toda atividade política" (JGB / BM 61, KSA 5.80) $)^{34}$.

Conclusão: o que é uma filosofia "antipolítica"?

Vê-se bem, afinal, que a filosofia de Nietzsche não é, de modo nenhum, inclusive no tema da política, uma filosofia simplesmente

33 Cf. também o fragmento 25 [355], KSA 11.106: "Hierarquia: aquele que determina os valores e dirige a vontade de milênios, guiando as naturezas mais elevadas, é o homem supremo".

34 Nietzsche indica nesse texto que se poderia exercer essa dominação mais sutil pela utilização da religião como instrumento de cultura.

68 | cadernos Nietzsche 32, 2013 
crítica e destrutiva - mas que ela reconhece, com efeito, as dificuldades inerentes a toda (re)construção autêntica, a necessidade de pensar suas condições prévias e, conjuntamente, a longa duração. Ao invés da precipitação que geralmente levou a perdurar os preconceitos não percebidos e os valores de decadência, Nietzsche propõe modos de pensamento e de criação que permitem, enfim, autenticamente "aprender de novo sobre a política" (Nachlass/FP outono 1885 - outono 18862 [57], KSA 12.88) e, sobretudo, "inventar alguma coisa em política" (Nachlass/FP abril-junho de 1885 34 [109], KSA 11.456-457), mas que excluem, efetivamente, toda atitude impaciente e precipitada. A censura de vaidade - nos dois sentidos do termo - feita à filosofia nietzschiana possui, portanto, a má compreensão de suas exigências próprias, de sua vontade de levar uma reflexão suficientemente radical e paciente, de "não saltar nenhuma etapa" necessária ao surgimento de uma novidade autêntica (Nachlass/FP verão - outono de 188315 [10], KSA 10.482).

É nesse contexto que tem sentido o epíteto "antipolítico" pelo qual Nietzsche caracteriza as épocas de cultura elevada e, por vezes, ele próprio: ser "antipolítico" é, por um lado, ser capaz de tomar distância e de se opor à (pequena) política tal como ela foi mais geralmente pensada, mas é também, e por isso mesmo, ser capaz de pensar um novo sentido de política - uma "grande política", da qual, entretanto, convém ainda refletir e realizar as condições preparatórias. Conforme os diversos sentidos etimológicos possíveis do prefixo "anti-", o indivíduo "antipolítico" vai contra a política de seu tempo, para que ele dê um outro sentido à política, do qual ele deve, todavia, ainda preparar o surgimento: uma filosofia anti-política nesse sentido é também ante-política, mas, nessa medida, ela não pode ser rigorosamente ser chamada $a$ política.

Deve-se compreender, portanto, que quando se pergunta, usando uma alternativa estrita, se Nietzsche é um pensador político, ou, ao contrário, um pensador apolítico, o conflito e a possibilidade da resposta depende, em grande medida, de um problema de linguagem, característica do autor de Além de bem e mal, que 
afirma, de fato, que a radical originalidade de sua filosofia requer necessariamente o uso de uma "nova linguagem". Pode-se dizer, em certo sentido, que a noção mesma de "política" encontra-se dissolvida, já que Nietzsche nega a autonomia da esfera política para reconduzi-la à "questão fundamental" da cultura e dos valores. Mas é preciso ver também que, por isso mesmo, Nietzsche pretende radicalizar e estender sua significação, ao pensar numa "grande política" que supere as noções de Estado, de nação, ou ainda de poder político, de modo a poder refletir acerca das condições de uma autêntica transformação da comunidade humana, entendida em seu sentido mais amplo. Do mesmo modo que Nietzsche critica e se afasta da filosofia tal como ela foi classicamente concebida e praticada, sem, entretanto, renunciar a ser filósofo - considerando-se mesmo como aquele que, pela primeira vez, colocou autenticamente em prática as exigências de radicalidade e de rigor inerentes à filosofia, seria necessário dizer que Nietzsche apenas critica e se afasta da significação usual da política para melhor repensar as condições de sua efetividade: para ele, o filósofo deve ser um indivíduo antipolítico se ele quiser poder pretender a um pensamento autenticamente político.

\begin{abstract}
This article aims to discuss the relationship between Nietzsche and politics. The German philosopher is generally seen as a thinker who fiercely criticized the politics of his time, but who possesses no practical proposal. Although the philosopher reinforces this image when he declares himself apolitical, the text shows in what sense Nietzsche is apolitical and even anti-political, and reveals the emergence of a new meaning for politics.
\end{abstract}

Key-words: culture - physio-psychology - great polítics - polítics 


\section{referências bibliográficas}

ANSELL-PEARSON, K. An Introduction to Nietzsche as Political Thinker. Cambridge: Cambridge University Press, 1994.

BROBJER, Th. The Absence of Political Ideals in Nietzsche's Writings. Nietzsche Studien, 27, 1998. p. 300-318

CONWAY, D. W. Nietzsche \& the Political. London: Routledge, 1997.

DENAT, C. "Ne pas rester lié à sa propre rupture". Solitude et communauté dans la philosophie de Nietzsche. Phaenex, v. 6, n. 2, Automne/Hiver 2011. p. 29-70, p. 46-55. Site: http://www.phaenex.uwindsor.ca/ojs/leddy/index.php/phaenex/ article/view/3478/2717.

DENAT, C.; WOTLING, P. Dictionnaire Nietzsche. Paris: Ellipses, 2013.

KAUFMANN, W. A. Nietzsche. Philosopher, Psychologist, Antichrist. Princeton: Princeton University Press, 1974. (réed.)

LEITER B. Nietzsche on Morality. London: Routledge, 2002.

MARTON, S. Nietzsche et la Révolution Française. Remarques sur la devise révolutionnaire. In: DENAT, C.; PIAZZESI,C. Nietzsche, penseur de la politique? Nietzsche, penseur du social? Pise-Paris: ETS/Editions d'Ariane, 2011. p. 115-127.

NIETZSCHE, F. Oeuvres philosophiques completes. Paris: Gallimard, 1968-1997. . Le Gai savoir. Trad.: P. Wotling. Paris: GF, 1997.

. Par-delà bien et mal. Trad.: P. Wotling. Paris: GF, 2000. . La Généalogie de la morale. Paris: Livre de Poche, 2000.

. Crépuscule des idoles. Trad.: P. Wotling. Paris: GF, 2005.

RUSSELL, B. History of Western Philosophy. London: Routledge, 1991.

SIEMENS, H. Nietzsche's Political Philosophy. A Review of Recent Literature. NietzscheStudien, 30, 2001. p. 509-526.

Artigo recebido em 12/12/2012.

Artigo aceito para publicação em 10/02/0213. 